\title{
Seasonal and interannual dynamics of polyphenols in Myriophyllum verticillatum and their allelopathic activity on Anabaena variabilis
}

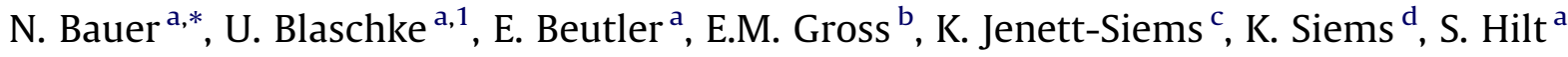 \\ ${ }^{a}$ Leibniz-Institute of Freshwater Ecology and Inland Fisheries, Müggelseedamm 301, 12587 Berlin, Germany \\ b Limnological Institute, Biology, University of Konstanz, PO Box 5560-659, 78457 Konstanz, Germany \\ ${ }^{\mathrm{c}}$ Free University Berlin, Institute of Pharmacy, Königin-Luise-Str. 2-4, 14195 Berlin, Germany \\ d Analyticon Discovery GmbH, Hermannswerder Haus 17, 14473 Potsdam, Germany
}

\begin{abstract}
A B S T R A C T
In 4 successive years, we investigated the seasonal and interannual variability of the total polyphenolic pool and of the individual polyphenolic compounds in Myriophyllum verticillatum, as well as their allelopathic activity in a small eutrophic lake. We tested whether nutrient availability explained interannual and seasonal changes in the production of polyphenols. There were no strong interannual variations in plant tissue carbon, nitrogen and phosphorus concentrations, while total phenolic compounds (TPC) significantly differed between years, especially in apical meristems (range: 38 $122 \mathrm{mg} \mathrm{g}{ }^{1}$ dry weight (DW)). Seasonal patterns, with maxima between May and July, changed between years. Partially confirming the carbon nutrient balance hypothesis sensu Bryant et al. [Bryant, J.P., Chapin III, F.S., Klein, D.R., 1983. Carbon/nutrient balance of boreal plants in relation to vertebrate herbivory. Oikos 40, 357 368], we found correlations between TPC and the $\mathrm{C} / \mathrm{N}$ (carbon/nitrogen) ratio in some but not all years, especially in apical meristems. Plant tissue phosphorus content accounted also for the variability in TPC in some years. Crude extracts of apical meristems always inhibited the growth of Anabaena variabilis, used as a target cyanobacterium. Plant TPC concentration and allelopathic activity were significantly correlated in all years except in 2005. Bioassay directed fractionation of $M$. verticillatum extracts coupled with LC MS analyses of the respective fractions revealed several isomers of HHDP di and tri galloylglucose apparently responsible for the allelopathic effects. The individual active compounds revealed a more distinct seasonal pattern compared to the pool of phenolic compounds in M. verticillatum, with a clear maximum in May, the ecologically most relevant period for inhibitory effects of submerged macrophytes on phytoplankton.
\end{abstract}

\section{Introduction}

The whorled water milfoil Myriophyllum verticillatum L. (Halor agaceae) is a perennial submerged macrophyte that is known to form dense monospecific stands in lakes and rivers (Caffrey and Monahan, 2006). It produces high amounts of polyphenolic compounds like other members of this family (Gross, 2003a). These polyphenols are considered to be important in the defence of plants against pathogens and both vertebrate and invertebrate herbivores (Smolders et al., 2000; Choi et al., 2002; Walenciak et al., 2002), and also play a major role in suppressing phytoplankton growth (Gross, 2003b; Hilt, 2006; Hilt et al.,

\footnotetext{
* Corresponding author. Tel.: +49 30 64181693; fax: +49 3064181682 .

E-mail addresses: bauer@igb-berlin.de (N. Bauer), hilt@igb-berlin.de (S. Hilt).

${ }^{1}$ Present address: Helmholtz Centre for Environmental Research - UFZ, Permoserstraße 15, 04318 Leipzig, Germany.
}

2006). To date, long term studies on the in situ variability of allelochemicals are lacking, and this study aims to bridge this gap.

A close relative, the Eurasian water milfoil M. spicatum L., contains up to $30 \%$ polyphenols based on dry weight in apical meristems and exhibits a strong inhibitory action against various cyanobacteria and algae (Gross et al., 1996; Körner and Nicklisch, 2002), which is mainly based on the polyphenol tellimagrandin II. Algicidal phenolic compounds are also present in $M$. verticillatum (Aliotta et al., 1992), and its allelopathic activity against phytoplankton has recently been shown in coexistence and in situ experiments (Hilt et al., 2006). The release of allelopathic substances may provide an advantage for submerged plants in the competition with phytoplankton and periphyton for light. Allelochemicals might thus contribute to the stabilization of clear water states in macrophyte dominated shallow eutrophic lakes (Hilt and Gross, 2008).

Allelopathic effects on phytoplankton and periphyton might be of special benefit for submerged macrophytes in spring and early 
summer when competition for light is strongest. The production of allelochemicals can be influenced by a variety of biotic and abiotic factors with consequences for their seasonal and interannual patterns of content and release. Until recently, the carbon nutrient balance hypothesis (CNBH; Bryant et al., 1983) was the most influential theory predicting phenotypic variation in secondary plant metabolites. It predicts that environmental conditions that give rise to a high carbon/nutrient ratio (e.g. high light and low nutrient availability) will result in an increased production of carbon based secondary compounds (CBSC). Levels of individual secondary metabolites, however, cannot adequately be predicted by this hypothesis (Koricheva et al., 1998; Hamilton et al., 2001), because single active compounds might be more important to the success of a plant than the pool of CBSC (Berenbaum, 1995; Gross, 2003a).

To test whether resource availability explains the intraspecific variability of allelochemicals in M. spicatum, Gross (2003a) investigated the impact of light and nitrogen on the production and release of total polyphenols and the allelopathically most active compound tellimagrandin II. She detected distinct differences in the reaction of total phenolic compounds and tellimagrandin II. These experiments were conducted using axenic cultures in a controlled environment to exclude the effects of additional factors such as herbivory or shading by epiphytes. Transferring the results of experimental studies to field situations, however, remains difficult.

In this study, we investigated the seasonal and interannual variability of total polyphenols and individual phenolic compounds in $M$. verticillatum under in situ conditions and the allelopathic activity of both individual and total phenolic compounds. We investigated a $M$. verticillatum stand in a small temperate lake in Berlin (Germany) during four subsequent vegetation periods to test whether (1) seasonal and interannual variability of concentrations of the total (TPC) or (2) individual phenolic compounds can be explained by nutrient availability, and whether (3) TPC or individual phenolic compounds correlate with the allelopathic activity of $M$. verticillatum on the cyanobacterium Anabaena variabilis.

\section{Materials and methods}

\subsection{Macrophytes}

Plant samples, visually checked for integrity, were collected monthly from May to September in a monospecific stand in Lake Krumme Laake (Berlin, Germany, $52^{\circ} 25.000^{\prime} \mathrm{N}, 13^{\circ} 41.150^{\prime} \mathrm{E}$ ) in a 4 year period (2004 2007). The lake has an area of about 1 ha, is only fed by rain and groundwater and is eutrophic and slightly humic with DOC concentrations of about $16 \mathrm{mg} \mathrm{L}^{1}$ (Beutler, 2007). Each month 10 shoots of $25 \mathrm{~cm}$ length per replicate were harvested at three different locations in the homogenous plant stand. Shoots were dissected into apices (apical meristems with internode length $<5 \mathrm{~mm}$ ), leaves and stems, shock frozen in liquid nitrogen, freeze dried, homogenized and stored dark and dry at room temperature until further processing. Total phosphorus (TP) and total nitrogen (TN) were measured according to Zwirnmann et al. (1999) in water samples taken in parallel to plant sampling.

\subsection{Concentrations of plant tissue total phenolic compounds, carbon, nitrogen and phosphorus}

Per plant sample, $20 \mathrm{mg}$ dry weight (DW) was extracted for $2 \mathrm{~h}$ at $16^{\circ} \mathrm{C}$ with $50 \%$ aqueous acetone. The extracts were analysed for total phenolic compounds (TPC) using the Folin Ciocalteau assay, modified after Gross et al. (1996) using only $40 \%$ of the given volume for sample and reagents. To determine the proportion of non phenolic compounds reacting with the Folin reagent, TPC content of extracts was measured again after treatment with insoluble polyvinyl polypyrrolidone (PVPP; P6755, Sigma Inc., St.
Louis, MO, USA). $50 \mu \mathrm{L}$ of a PVPP suspension ( $0.1 \mathrm{~g} \mathrm{~mL}{ }^{1}$ PVPP in ultrapure water) was added to $50 \mu \mathrm{L}$ of extract (raw extract dried in vacuo, resuspended in $50 \%$ aqueous methanol $[\mathrm{v} / \mathrm{v}]$ ) and shaken for $2 \mathrm{~h}$ at $14{ }^{\circ} \mathrm{C}$. Carbon (C) and nitrogen $(\mathrm{N})$ concentrations were analysed in a $\mathrm{C} / \mathrm{N}$ analyser (Vario EL, Elementar, Hanau, Germany). Phosphorus $(\mathrm{P})$ content was determined after digestion of $5 \mathrm{mg}$ plant DW with $2 \mathrm{~mL} \mathrm{H}_{2} \mathrm{SO}_{4}(5 \mathrm{M})$ and $2 \mathrm{~mL} \mathrm{H}_{2} \mathrm{O}_{2}$ (30\%) for $3 \mathrm{~h}$ at $120^{\circ} \mathrm{C}$ (Zwirnmann et al., 1999).

\subsection{Fractionation of crude extracts}

Crude extracts of $M$. verticillatum apices from 2004 were further separated by solid phase extraction (SPE). $2.25 \mathrm{ml}$ of crude extract was diluted with ultrapure water to a final concentration of $2 \%$ $\mathrm{MeOH}$ and passed over a preconditioned SPE C18 cartridge (Varian Bond Elut, $12 \mathrm{~mL}, 2 \mathrm{~g}$ sorbens) with a flow rate of about $3 \mathrm{~mL}$ min ${ }^{1}$. The cartridge was washed with $20 \mathrm{~mL}$ of $2 \% \mathrm{MeOH}$ and then stepwise eluted with $20 \mathrm{~mL}$ each of 2, 15, 20, 25, 30, 35, 75 and $100 \% \mathrm{MeOH}$. All 8 fractions were evaporated to dryness and resuspended in $50 \% \mathrm{MeOH}$ to a final concentration of $100 \mathrm{mg} \mathrm{DW} \mathrm{mL}^{1}$. HPLC analysis and TPC measurements were carried out as described for crude extracts.

\subsection{HPLC PDA analysis}

To compare the seasonal variability of TPC with that of individual phenolic compounds, extracts of apices (three replicates per month) of the vegetation period of 2004 were analysed by reversed phase high performance liquid chromatography with photodiode array detector (RP HPLC PDA). Aliquots of plant extracts (see Section 2.2) equivalent to $1 \mathrm{mg}$ plant DW were analysed by HPLC PDA (JASCO, Gross Umstadt, Germany; system consisting of an AS1555 autosampler, a 3 line solvent degasser DG 980 50, a low pressure mixer LG 980 02S, a PU980 pump, a column oven operated at $20^{\circ} \mathrm{C}$, and an MD910 photodiode array UV detector) using a Kromasil $100 \mathrm{C} 18$ column $(250 \mathrm{~mm} \times 4 \mathrm{~mm}$, $5 \mathrm{~mm} \times 4 \mathrm{~mm}$ pre column; KNAUER, Germany) with solvents A: acetic acid ( $1 \%[\mathrm{v} / \mathrm{v}]$ in water) and $\mathrm{B}$ : $\mathrm{MeOH}(100 \%)$ with an elution profile 040 min 5 60\% B, 4045 min 60 100\% B, 4565 min 100\% B, 6567 min 100 5\% B, 6775 min 5\% B. UV absorbing com pounds were detected at 280 and $254 \mathrm{~nm}$. The areas of detector signals recorded at $280 \mathrm{~nm}$ were used as quantitative measures for concentrations of individual compounds in M. verticillatum apices.

\subsection{LCMS analysis}

HPLC separation was carried out on a PerkinElmer PE Series 200 chromatograph employing a Merck Select B C18 column $(250 \mathrm{~mm} \times 4 \mathrm{~mm})$ operating at $23^{\circ} \mathrm{C}$. The mobile phase consisted of solvent A ( $5 \mathrm{mM}$ ammoniumformiate buffer with $0.1 \%$ formic acid) and solvent $B$ (acetonitrile:methanol $1: 1$ with $5 \mathrm{mM}$ ammoniumformiate and $0.1 \%$ formic acid); initial conditions were $15 \%$ B followed by a linear gradient to $100 \%$ B over 30 min at a flow rate of $0.9 \mathrm{mLmin}{ }^{1}$. Compounds were detected using a UV detector (Merck Hitachi) at a wavelength of $250 \mathrm{~nm}$, an evaporative light scattering detector (ELSD Sedex 75, nebulising temperature $35^{\circ} \mathrm{C}$ ), and by electrospray MS (Sciex API 165, Applied Biosystems, with a turbo ion spray source using MassChrom 1.5.1. software, switching mode between positive and negative electro spray, scanning from $m / z 100$ 1500).

\subsection{Bioassays}

The inhibitory activity of crude extracts (raw extract dried in vacuo and resuspended in $50 \%$ methanol $[\mathrm{v} / \mathrm{v}]$ in water) of the apices of $M$. verticillatum was tested against the cyanobacterium $A$. 
variabilis P9 (strain ATCC 29413) using an agar diffusion assay (ADA). The test organism was cultivated and the ADA was prepared as described in Gross et al. (1991). Three different aliquots of crude methanolic extracts representing $0.5,1$ and $2 \mathrm{mg}$ plant DW were pipetted onto agar plates (cyanobacteria medium solidified with $1 \%$ agar; three replicates per month). The lower agar layer was then overlaid with $7.5 \mathrm{~mL}$ of a suspension of A. variabilis (final OD at $530 \mathrm{~nm}$ of $0.04 \mathrm{AU}$ per $10 \mathrm{~mL}$ ) in cyanobacteria medium to which $2.5 \mathrm{~mL}$ boiling $4 \%$ agar were added, yielding a suspension ready to pour over the base agar. Inhibitory activities could be seen by clearing areas around the spots after 7 days $(2004,2005)$ or 14 days (2006, 2007) of incubation at $28{ }^{\circ} \mathrm{C}$ and constant illumination ( $80 \mu \mathrm{mol}$ photons $\mathrm{m}^{2} \mathrm{~s}^{1}$ ). The inhibitory effects were quantified by measuring the diameter and calculating the area of the clearing zones. Due to different incubation times absolute values of clearing areas can only be compared between seasons of each year, not between years. For comparison, all data of clearing areas of a single year were normalized to $100 \%$ (maximum clearing area of the respective year). To identify the major allelopathically active compounds, the inhibitory effect of different fractions of crude extracts of $M$. verticillatum apices from 2004, separated by SPE, was determined in ADAs with $2 \mathrm{mg}$ plant DW.

\subsection{Statistical analysis}

We tested plant tissue TPC, $\mathrm{C} / \mathrm{N}$ ratio, $\mathrm{N}$ and $\mathrm{P}$ concentrations as well as bioassay data for seasonal and interannual differences using non parametric Kruskal Wallis tests and subsequent multi ple comparisons using Mann Whitney $U$ tests with $p=0.05$ divided by the number of all possible comparisons. Mann Whitney $U$ tests were also used to detect treatment effect in bioassays. Since different plant parts (apices, leaves and stems) significantly differed in their TPC, C, N and P content, the effect of year and season were tested separately for each plant part. Tests of correlation between TPC and C/N and between TPC and P were performed using Spearman's rank correlation at $p<0.05$. To compare HPLC peak areas during different seasons and TPC in apices of different water depths, we used one way analysis of variance (ANOVA) and subsequent Tukey's post hoc tests at $p<0.05$. All data analysed by parametric tests were tested for normal distribution and homogeneity of variance. All statistical analyses were carried out using SPSS for Windows 14.0.

\section{Results}

\subsection{Seasonal and interannual dynamics of TPC, $C / N$ ratio, $N$ and $P$} concentrations in $M$. verticillatum

TP and TN concentrations in the water of Lake Krumme Laake during the vegetation period of $M$. verticillatum from May to September 20042007 ranged between $3060 \mu \mathrm{g} \mathrm{L}^{1}$ and 0.6 $1.4 \mathrm{mg} \mathrm{L}{ }^{1}$, respectively, and were not significantly different between years. TPC as well as $\mathrm{C} / \mathrm{N}$ ratio, $\mathrm{N}$ and $\mathrm{P}$ concentrations significantly differed between apices, leaves and stems of $M$. verticillatum with highest TPC, $\mathrm{N}$ and $\mathrm{P}$ concentrations in apices (Fig. 1, Table 1$)$. The highest $\left(120 \mathrm{mg} \mathrm{g}{ }^{1} \mathrm{DW}\right.$ in apices in May 2004) and lowest concentration of TPC (17 mg g ${ }^{1} \mathrm{DW}$ in leaves in May 2005) varied almost by an order of magnitude in 4 years. PVPP assays revealed on average $13 \%$ (range $422 \%$ ) non phenolic compounds being detected as TPC. Significant interannual differences were recorded for all plant parts for TPC (Table 2), but not for $\mathrm{C} / \mathrm{N}$ ratio, $\mathrm{N}$ and $\mathrm{P}$ concentrations (Kruskal Wallis test, $p<0.05)$, when data of all seasons were pooled. Concentrations of TPC in apices and leaves were highest in 2004 (Table 2). Interannual differences in TPC were strongest in May (Fig. 1). Significant monthly differences of the growing season were measured for all plant parts for $\mathrm{C} / \mathrm{N}$ ratios, $\mathrm{N}$ and $\mathrm{P}$ concentrations, but not for TPC when data of all years were pooled. We found highest $\mathrm{C} / \mathrm{N}$ ratios and lowest $\mathrm{N}$ concentrations in June and July and increased $\mathrm{P}$ concentrations in all plant parts towards the end of the growing season (Kruskal Wallis test, $p<0.0001$, multiple com parisons at $p<0.05 /$ number of comparisons (10), $N=180$ ). Correlations between TPC and C/N and between TPC and P were mostly weak or not significant (Table 3). Pooling data of all years for the individual plant parts resulted in a weak positive relation between TPC and C/N ratio for apices and leaves (although an inverse relation was found for apices in 2005), and a weak inverse relation between TPC and P concentration (Table 3 ).

\subsection{Seasonal dynamics of individual compounds}

HPLC PDA analysis of extracts of M. verticillatum apices of 2004 revealed the presence of nine major compounds (Fig. 2). Com pound no. 1 with a retention time of $7 \mathrm{~min}$ was identified as gallic acid based on its UV spectrum and co chromatography with the pure compound (Lutz, 2004). The other major HPLC PDA signals refer to several hydrolysable tannins, among them gallo and ellagitannins and at least one flavonoid glycoside based on preliminary LCMS analyses (Tables 4 and 5). Most of the major compounds showed a clear seasonal pattern with highest concentrations present in May and lowest in September (Fig. 2, one way ANOVA at $p<0.05$, Tukey's post hoc test). HPLC PDA peak areas of six compounds were positively correlated with TPC (Table 5). Gallic acid showed an opposite pattern and peak areas were inversely related to TPC (Fig. 2, Table 5). None of the compounds significantly correlated with the $\mathrm{C} / \mathrm{N}$ ratio, but six were inversely correlated with $\mathrm{P}$ (Table 5). In fact, correlation coefficients of HPLC areas of these individual phenolic compounds with P were similar to those of TPC with P (Tables 3 and 5).

\subsection{Allelopathic activity of M. verticillatum extracts and SPE fractions}

Crude extracts of apices of $M$. verticillatum of all years significantly inhibited the growth of $A$. variabilis as compared to $\mathrm{MeOH}$ controls in the ADA when applied in equivalents of $2 \mathrm{mg}$ plant DW (Fig. 3, Mann Whitney $U$ tests at $p<0.05$ ). The application of $0.5 \mathrm{mg}$ plant DW only resulted in a significant inhibition in 2006 (except for June), and that of $1 \mathrm{mg}$ plant DW in 2005 (all seasons), 2006 (except for June) and 2007 (only June) (Fig. 3). A significant correlation between TPC and the clearing area of crude extracts of $M$. verticillatum apices was found for all years except 2005 (Spearman's rank correlation, 2004: $r=0.692$, $p=0.004 ; 2006: r=0.628, p=0.012 ; 2007: r=0.628, p=0.012$ ). Significant seasonal differences in the inhibitory activity (of $2 \mathrm{mg}$ DW) were found only in 2005 and 2007, and were weaker in the other 2 years (Kruskal Wallis test, 2004: $p=0.064$; 2005: $p=0.017 ; 2006: p=0.094 ; 2007: p=0.045$ ).

Significant inhibitory effects of SPE fractions of $M$. verticillatum apices from 2004 on the growth of $A$. variabilis were found in four fractions: 25, 30, 35 and 75\% $\mathrm{MeOH}$ (Fig. 4, Mann Whitney $U$ tests at $p<0.05$ ). These fractions mainly contained the compounds no. 6 (25\%), 6 and 7a/b (30\%), 7a/b and 8 (35\%) and 9 (75\%) (Table 4). A significant correlation between TPC and clearing area was found when pooling fractions 25, 30 and 35\% (Spearman's rank correlation, $r=0.918, p<0.001)$.

\section{Discussion}

\subsection{Intraspecific variation of TPC in M. verticillatum}

Submerged macrophytes are assumed to have lower concentra tions of phenolic compounds than emergent and floating leaved 


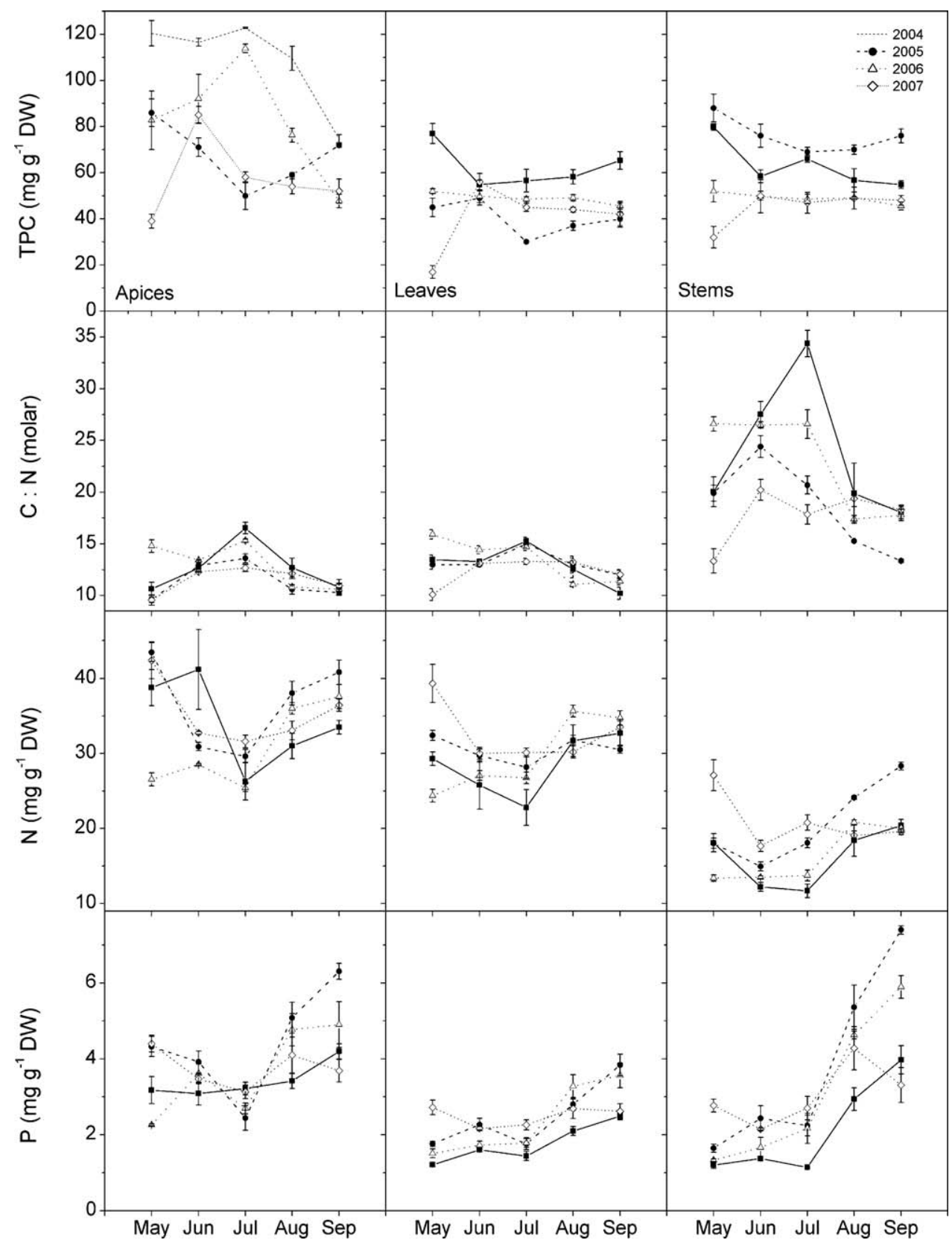

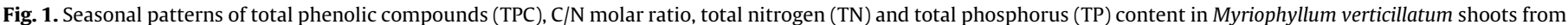
Lake Krumme Laake (Berlin, Germany) during the growing seasons 2004-2007. Data presented are means \pm standard error $(n=3$ ).

aquatic plants due to their lower vulnerability to herbivory, lower exposure to UV B radiation and lower availability of light and inorganic carbon (Smolders et al., 2000). M. verticillatum and $M$. spicatum, and other members of this genus, are exceptions, probably

Table 1

Differences in concentrations of total phenolic compounds (TPC), C/N molar ratios and nitrogen $(\mathrm{N})$ and phosphorus $(\mathrm{P})$ contents between apices, lower leaves and stems of M. verticillatum between May and September 2004-2007. Data represent medians, those sharing the same letter are not significantly different at $p<0.017$ (Kruskal-Wallis test, multiple comparisons at $p<0.05 /$ number of comparisons ( 3 ), $N=180)$.

\begin{tabular}{|c|c|c|c|c|}
\hline & Apices & Leaves & Stems & $p$ \\
\hline $\mathrm{TPC}\left(\mathrm{mg} \mathrm{g}{ }^{1} \mathrm{DW}\right)$ & $76 \mathrm{c}$ & 48 a & $56 \mathrm{~b}$ & $<0.0001$ \\
\hline $\mathrm{C} / \mathrm{N}$ molar ratio & $12.0 \mathrm{a}$ & $13.1 \mathrm{~b}$ & $19.2 \mathrm{c}$ & $<0.0001$ \\
\hline $\mathrm{N}\left(\mathrm{mg} \mathrm{g}{ }^{1} \mathrm{DW}\right)$ & $33.7 \mathrm{c}$ & $30.4 \mathrm{~b}$ & 18.9 a & $<0.0001$ \\
\hline $\mathrm{P}\left(\mathrm{mg} g{ }^{1} \mathrm{DW}\right)$ & $3.71 \mathrm{~b}$ & $2.21 \mathrm{a}$ & $2.51 \mathrm{a}$ & $<0.0001$ \\
\hline
\end{tabular}

due to the specific allelochemical function of their polyphenols (Gross et al., 1996; Hilt et al., 2006). Maximum TPC concentrations of $M$. verticillatum apices in our study were 2.5 times lower than those recorded for M. spicatum (Gross et al., 1996). In our study, TPC

Table 2

Interannual differences in concentrations of total phenolic compounds (TPC) in apices, lower leaves and stems of $M$. verticillatum between May and September 2004-2007. Data represent medians, those sharing the same letter are not significantly different at $p<0.008$ (Kruskal-Wallis test, multiple comparisons at $p<0.05 /$ number of comparisons (6), $N=180$ ).

\begin{tabular}{llrllll}
\hline & & 2004 & 2005 & 2006 & 2007 & $p$ \\
\hline \multirow{2}{*}{ TPC (mg g $\left.{ }^{1} \mathrm{DW}\right)$} & Apices & $116 \mathrm{c}$ & $69 \mathrm{ab}$ & $91 \mathrm{bc}$ & $55 \mathrm{a}$ & $<0.0001$ \\
& Leaves & $60 \mathrm{c}$ & $39 \mathrm{a}$ & $49 \mathrm{~b}$ & $44 \mathrm{ab}$ & $<0.0001$ \\
& Stems & $64 \mathrm{~b}$ & $74 \mathrm{c}$ & $47 \mathrm{a}$ & $46 \mathrm{a}$ & $<0.0001$ \\
\hline
\end{tabular}


Table 3

Correlations (Spearman's rank, $r$ : correlation coefficient) between total phenolic compounds (TPC), C/N molar ratios and phosphorus contents (P) in apices, lower leaves and stems of $M$. verticillatum between May and September 2004-2007 (bold: significant at ${ }^{*} p<0.05$ or ${ }^{* *} p<0.01$ ).

\begin{tabular}{|c|c|c|c|c|c|c|c|}
\hline & & \multicolumn{2}{|l|}{ Apices } & \multicolumn{2}{|l|}{ Leaves } & \multicolumn{2}{|l|}{ Stems } \\
\hline & & $r$ & $p$ & $r$ & $p$ & $r$ & $p$ \\
\hline \multirow[t]{5}{*}{ TPC-C/N } & 2004 & 0.519 & 0.051 & -0.147 & 0.602 & 0.394 & 0.146 \\
\hline & 2005 & $-0.592^{*}$ & 0.020 & -0.106 & 0.708 & -0.075 & 0.790 \\
\hline & 2006 & 0.831* & $<0.0001$ & 0.364 & 0.182 & 0.386 & 0.156 \\
\hline & 2007 & $0.536^{*}$ & 0.040 & $0.654^{*}$ & 0.008 & $0.611^{*}$ & 0.016 \\
\hline & 2004-2007 & $0.429^{* *}$ & 0.001 & $0.265^{*}$ & 0.041 & 0.227 & 0.081 \\
\hline \multirow[t]{5}{*}{ TPC-P } & 2004 & $-0.629^{*}$ & 0.012 & -0.247 & 0.375 & $-0.686^{*}$ & 0.005 \\
\hline & 2005 & 0.363 & 0.183 & 0.104 & 0.712 & -0.201 & 0.473 \\
\hline & 2006 & $-0.639 *$ & 0.010 & -0.407 & 0.132 & -0.232 & 0.405 \\
\hline & 2007 & -0.296 & 0.283 & $-0.654^{*}$ & 0.008 & -0.443 & 0.098 \\
\hline & 2004-2007 & $-0.382^{* *}$ & 0.003 & $-0.357^{* *}$ & 0.005 & $-0.267^{*}$ & 0.040 \\
\hline
\end{tabular}

Table 4

Polyphenolic compounds detected in apices of M. verticillatum in 2004 (HHDP: hexahydroxydiphenoyl).

\begin{tabular}{rlccl}
\hline No. $^{\text {a }}$ & $\begin{array}{l}\text { Retention time } \\
\text { in HPLC-PDA (min) }\end{array}$ & $\begin{array}{l}\text { Retention time } \\
\text { in LCMS (min) }\end{array}$ & {$[\mathrm{M}-\mathrm{H}]$} & Compound \\
\hline 4 & 17 & 7.03 & 785 & HHDP-di-galloylglucose \\
5 & 20 & 7.70 & 635 & Tri-galloylglucose \\
6 & 22 & 8.32 & 785 & HHDP-di-galloylglucose \\
$7 \mathrm{a}$ & 24 & 9.09 & 785 & HHDP-di-galloylglucose \\
$7 \mathrm{~b}$ & 25 & 9.97 & 937 & HHDP-tri-galloylglucose \\
8 & 28 & 10.20 & 937 & HHDP-tri-galloylglucose \\
9 & 35 & 13.74 & 447 & Quercetin-glycoside \\
\hline
\end{tabular}

${ }^{a}$ No. referring to the nine major compounds and the related number in Fig. 2 and Table 5.

concentrations were highest in apices, and extracts of these organs were considered for evaluating the allelopathic effect of $M$. verticillatum. This is consistent with Häring et al. (2007), who found that the allocation of fixed carbon into condensed tannins was highest during the early developmental phase and later resources were allocated more to biomass accumulation.

We found considerable intra and interannual variations in the TPC of M. verticillatum. TPC in apices varied by a factor of 1.74 .0 between years, and by a factor of 1.82 .8 within years. In various submerged macrophytes, Smolders et al. (2000) found intraspecific variations up to a factor of 46 in leaves. No referral was made to the depth of the plant stands, the age of the leaves or nutrient conditions in the lakes, all of which might contribute to this higher variability. Although no consistent seasonal pattern of TPC concentrations in $M$. verticillatum of Lake Krumme Laake was found, major variability of TPC concentrations in May indicate a potentially high impact of biotic and abiotic factors on the production of these allelochemicals in spring. At the beginning of

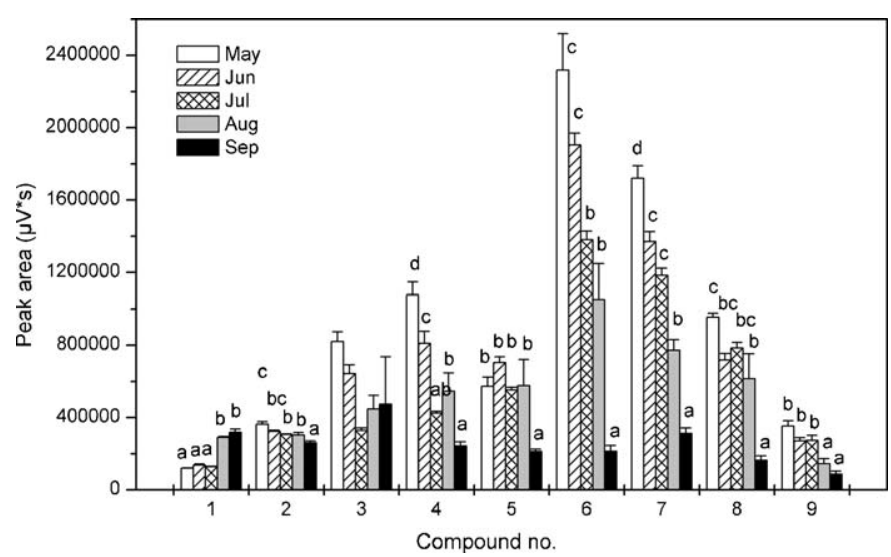

Fig. 2. Seasonal variation of HPLC-PDA peak areas at $280 \mathrm{~nm}$ of nine main compounds in apices of $M$. verticillatum during the growing season 2004. Data presented are means \pm standard error $(n=3)$. Different letters indicate significant differences between seasons (one-way ANOVA, Tukey's post hoc test at $p<0.05$ ).

the growing season, when plants have not yet reached the water surface, higher TPC concentrations can be essential in the competition with phytoplankton for light. Gross (2000) found that spatio temporal variations in TPC concentrations in $M$. spicatum were less pronounced than concentrations of tellima grandin II, its major allelochemical. Our results confirm these findings for the major allelopathically active compounds in $M$. verticillatum (see Section 4.3), showing a more distinct seasonal pattern and a clear maximum in May compared to the pool of phenolic compounds (Fig. 2). This supports the view that in order to evaluate the ecological impact of allelopathic effects in $M$. verticillatum, it is not sufficient to focus only on the pool of phenolic compounds but to consider also single active compounds. Individual compounds might be differentially regulated by abiotic factors than the pool of phenolic compounds, reflecting challenges from biotic stressors, as found for M. spicatum (Gross, 2003b).

\subsection{Impact of nutrient availability on TPC}

The seasonal variability of TPC concentrations in $M$. verticilla tum in Lake Krumme Laake was not strongly related to plant tissue nutrient content. The same holds true for the interannual TPC variability, probably because the nutrient content in the plants did not change significantly between years. Different conceptual models (CNBH: Bryant et al., 1983; growth differentiation model: Herms and Mattson, 1992; protein competition model: Jones and Hartley, 1999) predict higher allocation to phenolics when nutrients are limiting. In our study, $\mathrm{N}$ and $\mathrm{P}$ concentrations in apices and leaves were always well above limiting levels of 13 and $1.3 \mathrm{mg} \mathrm{g}{ }^{1} \mathrm{DW}$, respectively (Gerloff and Krombholz, 1966), while only stems sometimes fell below these thresholds. The lack of

Table 5

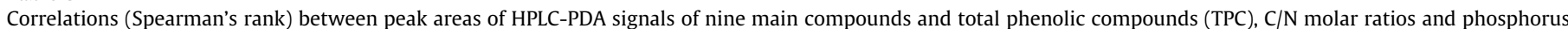

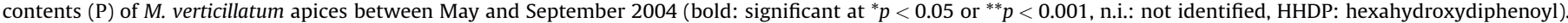

\begin{tabular}{|c|c|c|c|c|c|c|c|}
\hline \multirow[t]{2}{*}{ No. } & \multirow[t]{2}{*}{ Name } & \multicolumn{2}{|l|}{ TPC } & \multicolumn{2}{|l|}{$\mathrm{C} / \mathrm{N}$} & \multicolumn{2}{|l|}{$\mathrm{P}$} \\
\hline & & $r$ & $p$ & $r$ & $p$ & $r$ & $p$ \\
\hline 1 & Gallic acid & $-0.726^{* *}$ & 0.002 & 0.005 & 0.985 & 0.450 & 0.092 \\
\hline 2 & n.i. & 0.616* & 0.014 & -0.127 & 0.652 & $-0.643^{* *}$ & 0.010 \\
\hline 3 & n.i. & 0.050 & 0.859 & -0.188 & 0.503 & -0.361 & 0.187 \\
\hline 4 & HHDP-di-galloylglucose & 0.486 & 0.066 & -0.252 & 0.365 & $-0.646^{* *}$ & 0.009 \\
\hline 5 & Tri-galloylglucose & $0.649^{* *}$ & 0.009 & 0.331 & 0.229 & $-0.657^{* *}$ & 0.008 \\
\hline 6 & HHDP-di-galloylglucose & $0.660^{* *}$ & 0.007 & -0.075 & 0.790 & $-0.582^{*}$ & 0.023 \\
\hline 7 & Mixture of HHDP-di- and -tri-galloylglucose & $0.631^{*}$ & 0.012 & -0.123 & 0.661 & $-0.636^{*}$ & 0.011 \\
\hline 8 & HHDP-tri-galloylglucose & $0.783^{* *}$ & 0.001 & 0.039 & 0.889 & -0.471 & 0.076 \\
\hline 9 & Quercetin-glycoside & $0.712^{* *}$ & 0.003 & 0.027 & 0.924 & $-0.625^{*}$ & 0.013 \\
\hline
\end{tabular}




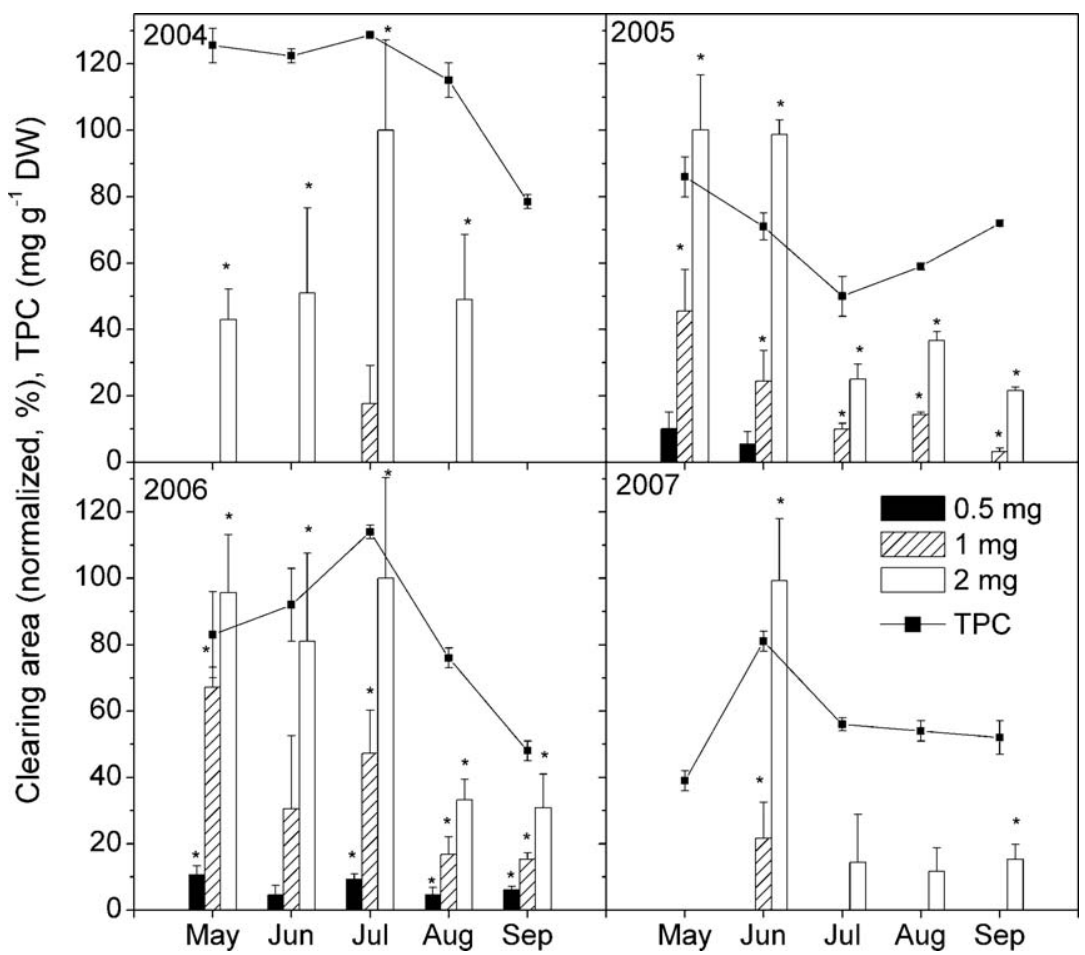

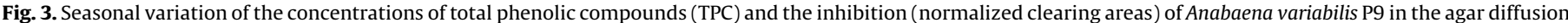

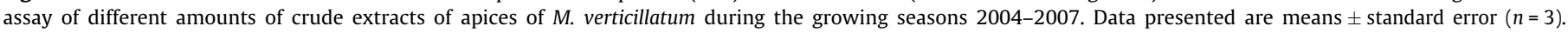
*Significantly different from control (Mann-Whitney $U$ test at $p<0.05$ ).

correlation between the TPC and the respective $\mathrm{C} / \mathrm{N}$ ratio in $M$. verticillatum apices may thus be attributed to sufficient nutrient availability. Gross (2003a) also did not find a correlation between TPC and C/N ratio, but did for tellimagrandin II in M. spicatum. However, our findings of weak negative correlations between TPC and $\mathrm{P}$ in 2 years support the rather scarce information on the impact of P availability on TPC so far. Hättenschwiler et al. (2003) found increasing TPC levels with decreasing P availability in leaf litter of montane rainforest tree species.

Other parameters such as light availability might even be more important than nutrient availability in predicting concentrations of plant phenolics, e.g. for TPC in M. spicatum (Gross, 2003a), for phlorotannins in brown seaweeds (Pavia and Toth, 2000) or for hydrolysable tannins in general (Koricheva et al., 1998). Detecting

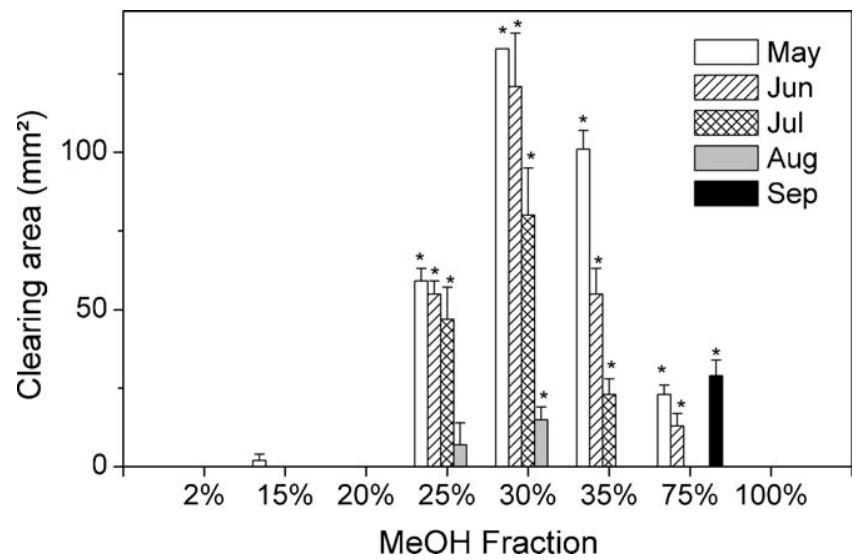

Fig. 4. Seasonal variation of the inhibition of Anabaena variabilis P9 in the agar diffusion assay of different $\mathrm{MeOH}$ fractions of crude extracts (solid phase extraction) of apices of $M$. verticillatum during the growing season 2004. Data presented are means \pm standard error $(n=3)$. *Significantly different from control (Mann-Whitney $U$ test at $p<0.05$ ). the light availability for submerged macrophytes in situ, however, is difficult as both phytoplankton and epiphyton are contributing to shading and are subject to seasonal changes. Trophic interac tions and abiotic factors such as fish predation on zooplankton or epiphyton grazing macroinvertebrates in turn may alleviate light limitation for submerged macrophytes (e.g. Hrbáček et al., 1961; Sand Jensen and Borum, 1991).

\subsection{Allelopathic activity}

ADAs with $M$. verticillatum extracts showed significant inhibitory effects against the cyanobacterium $A$. variabilis. Cyanobacteria are often used for the detection of allelopathic effects of submerged macrophytes and proved to be a sensitive group as compared to e.g. chlorophytes (Hilt and Gross, 2008). Similar tests were used to show the allelopathic activity of M. spicatum (Gross et al., 1996), Najas marina and Ceratophyllum demersum (Gross et al., 2003), Elodea canadensis and E. nuttallii (Erhard and Gross, 2006) as well as Stratiotes aloides (Mulderij et al., 2007). Direct comparisons between these tests to rank allelopathic activities of different macrophyte species remain difficult, as incubation times often differed. Although experiments conducted with extracts cannot give convincing ecological proof for allelopathic interactions (Gross et al., 2007), they still provide useful information about active compounds and their seasonal and interannual variability. We can assume that a certain amount of internal TPC is exuded by Myriophyllum species and thus affects epiphytes and phytoplankton. In M. spicatum, the proportion of exuded TPC even increased under low light, supporting the function of phenolic compounds in allelopathic interactions (Gross, 2003a). For M. verticillatum, TPC and allelopathic activity correlated in most cases, corroborating the general suitability of TPC as an indicator for the allelopathic activity also of this species. Still, only a few compounds seem to contribute significantly to this activity. Bioassay directed fractionation indicated that in $M$. verticillatum extracts, four phenolic compounds with HPLC PDA 
retention times of $22,24,25$ and 28 min referring to compound nos. 6 , $7 \mathrm{a}, 7 \mathrm{~b}$ and 8 , were mainly responsible for the inhibitory effect. These compounds are closely related, if not identical to the ellagitannin tellimagrandin II (1,2,3 tri $O$ galloyl 4,6 $(S)$ hexahydroxydiphe noyl $\beta$ D glucose $=a$ HHDP tri galloylglucose), the major allelo pathically active compound in M. spicatum (Gross et al., 1996). Final proof of the correct stereochemistry of these compounds is in preparation (Jenett Siems, Siems, Gross, Bauer and Hilt, unpublished results). HPLC PDA analysis suggested that these compounds are not identical with the three phenylpropanoid glucosides detected by Aliotta et al. (1992). The seasonal pattern of their inhibitory effect on the tested cyanobacterium clearly points to a maximum allelopathic activity of M. verticillatum in May and June. Exudation rates for single compounds were not determined, but TPC exudation rates in $M$. verticillatum were also highest in May (Hilt et al., 2006).

\section{Acknowledgements}

We are grateful to Rüdiger Biskupek, Annika Becker, Kay Brennecke and Max Klomsdorff for help during field sampling, Marianne Graupe, Antje Lüder, Elke Zwirnmann, Hans Jürgen Exner and Thomas Rossoll (IGB) for the determination of nutrient concentrations and Claudia Feldbaum (University of Konstanz) for assisting with the TPC measurements. Special thanks to Mario Brauns (IGB) for statistical advice and Thomas Shatwell for linguistic improvement. N.B. was financially supported by NaföG, a national grant of Berlin for PhD students and S.H. partially by the "Berliner Programm zur Förderung der Chancengleichheit von Frauen in Forschung und Lehre". Research at the University of Konstanz during a guest stay of S.H. was supported by the German Research Foundation (SFB 454, project A2 to E.M.G.). We acknowl edge the thoughtful contributions of the anonymous reviewers.

\section{References}

Aliotta, G., Molinaro, A., Monaco, P., Pinto, G., Previtera, L., 1992. Three biologicallyactive phenylpropanoid glucosides from Myriophyllum verticillatum. Phytochemistry $31,109-119$.

Berenbaum, M.R., 1995. The chemistry of defence: theory and practice. Proc. Natl. Acad. Sci. 92, 2-8.

Beutler, E., 2007. Allelopathische Wachstumshemmung verschiedener phytoplankton-Arten durch Myriophyllum verticillatum. Diploma Thesis. University of Greifswald.

Bryant, J.P., Chapin III, F.S., Klein, D.R., 1983. Carbon/nutrient balance of boreal plants in relation to vertebrate herbivory. Oikos 40, 357-368

Caffrey, J.M., Monahan, C., 2006. Control of Myriophyllum verticillatum L. in Irish canals by turions removal. Hydrobiologia 570, 211-215.

Choi, C., Bareiss, C., Walenciak, O., Gross, E.M., 2002. Impact of polyphenols on the growth of the aquatic herbivore Acentria ephemerella (Lepidoptera: Pyralidae). J. Chem. Ecol. 28, 2245-2256.

Erhard, D., Gross, E.M., 2006. Allelopathic activity of Elodea canadensis and Elodea nuttallii against epiphytes and phytoplankton. Aquat. Bot. 85, 203-211.

Gerloff, G.C., Krombholz, P.H., 1966. Tissue analysis as a measure of nutrient availability for the growth of angiosperm aquatic plants. Limnol. Oceanogr. $11,529-537$.
Gross, E.M., 2000. Seasonal and spatial dynamics of allelochemicals in the submersed macrophyte Myriophyllum spicatum L. Verh. Internat. Verein. Limnol. 27, 2116-2119.

Gross, E.M., 2003a. Differential response of telimagrandin II and total bioactive hydrolysable tannins in an aquatic angiosperm to changes in light and nitrogen. Oikos 103, 497-504.

Gross, E.M., 2003b. Allelopathy of aquatic autotrophs. Crit. Rev. Plant Sci. 22, $313-$ 339.

Gross, E.M., Wolk, C.P., Jüttner, F., 1991. Fischerellin, a new allelochemical from the freshwater cyanobacterium Fischerella muscicola. J. Phycol. 27, 686-692.

Gross, E.M., Meyer, H., Schilling, G., 1996. Release and ecological impact of algicidal hydrolysable polyphenols in Myriophyllum spicatum. Phytochemistry 41,133138.

Gross, E.M., Erhard, D., Ivanyi, E., 2003. Allelopathic activity of Ceratophyllum demersum L. and Najas marina ssp. intermedia (Wolfgang) Casper. Hydrobiologia 506, 583-589.

Gross, E.M., Hilt, S., Lombardo, P., Mulderij, G., 2007. Searching for allelopathy in action-state of the art and open questions. Hydrobiologia 584, 77-88.

Häring, D.A., Suter, D., Amrhein, N., Lüscher, A., 2007. Biomass allocation is an important determinant of the tannin concentration in growing plants. Ann. Bot. 99, 111-120.

Hättenschwiler, S., Hagerman, A.E., Vitousek, P.M., 2003. Polyphenols in litter from tropical montane forests across a wide range in soil fertility. Biogeochemistry $64,129-148$.

Hamilton, J.G., Zangerl, A.R., DeLucia, E.H., Berenbaum, M.R., 2001. The carbonnutrient balance hypothesis: its rise and fall. Ecol. Lett. 4, 86-95.

Herms, D.A., Mattson, W.J., 1992. The dilemma of plants: to grow or defend. Q. Rev. Biol. 67, 283-335.

Hilt, S., 2006. Allelopathic inhibition of epiphytes by submerged macrophytes. Aquat. Bot. 85, 252-256.

Hilt, S., Ghobrial, M.G.N., Gross, E.M., 2006. In situ allelopathic potential of Myriophyllum verticillatum (Haloragaceae) against selected phytoplankton species. J. Phycol. 42, 1189-1198.

Hilt, S., Gross, E.M., 2008. Can allelopathically active submerged macrophytes stabilize clear-water states in shallow eutrophic lakes? Bas. Appl. Ecol. 9, 422-432.

Hrbáček, J., Dvořáková, M., Kořínek, V., Procházková, L., 1961. Demonstration of the effect of fish stock on species composition and the intensity of metabolism of the whole plankton association. Verh. Internat. Verein. Limnol. 14, 192-195.

Jones, C.G., Hartley, S.E., 1999. A protein competition model of phenolic allocation. Oikos 86, 27-44.

Körner, S., Nicklisch, A., 2002. Allelopathic growth inhibition of selected phytoplankton species by submerged macrophytes. J. Phycol. 38, 862-871.

Koricheva, J., Larsson, S., Haukioja, E., Keinänen, M., 1998. Regulation of woody plant secondary metabolism by resource availability: hypothesis testing by means of meta-analysis. Oikos 83, 212-226.

Lutz, S., 2004. Analyse phenolischer Sekundärmetabolite in Myriophyllum spp. (Haloragaceae). Diploma Thesis. University of Konstanz.

Mulderij, G., Mau, B., Van Donk, E., Gross, E.M., 2007. Allelopathic activity of Stratiotes aloides on phytoplankton-towards identification of allelopathic substances. Hydrobiologia 584, 89-100.

Pavia, H., Toth, G.B., 2000. Influence of light and nitrogen on the phlorotannin content of the brown seaweeds Ascophyllum nodosum and Fucus vesiculosus. Hydrobiologia 440, 299-305.

Sand-Jensen, K., Borum, J., 1991. Interactions among phytoplankton, periphyton, and macrophytes in temperate freshwaters and estuaries. Aquat. Bot. 41, 137175.

Smolders, A.J.P., Vergeer, L.H.T., Van der Velde, G., Roelofs, J.G.M., 2000. Phenolic contents of submerged, emergent and floating leaves of aquatic and semiaquatic macrophyte species: why do they differ? Oikos 91, 307-310.

Walenciak, O., Zwisler, W., Gross, E.M., 2002. Influence of Myriophyllum spicatum derived tannins on gut microbiota of its herbivore Acentria ephemerella (Lepidoptera: Pyralidae). J. Chem. Ecol. 28, 2045-2056.

Zwirnmann, E., Krüger, A., Gelbrecht, J., 1999. Analytik im Zentralen Chemielabor des IGB. Berichte des IGB 9, 3-24. 